\title{
Partitioning and transmutation strategy R\&D for nuclear spent fuel: the SACSESS and GENIORS projects
}

\author{
Stéphane Bourg ${ }^{1, *}$, Andreas Geist ${ }^{2}$, Jean-Marc Adnet ${ }^{1}$, Chris Rhodes ${ }^{3}$, and Bruce C. Hanson ${ }^{4}$ \\ ${ }^{1}$ Research Department on Mining and Fuel Recycling Processes, CEA Marcoule, Bat 400, 30207 Bagnols-sur-Cèze, France \\ ${ }^{2}$ KIT-INE, Karlsruhe, Germany \\ 3 NNL-UK, Sellafield, UK \\ ${ }^{4}$ University of Leeds, Leeds, UK
}

Received: 12 March 2019 / Accepted: 4 June 2019

\begin{abstract}
Processes such as PUREX allow the recovery and reuse of the uranium and the plutonium of GEN II/ GEN III reactors and are being adapted for the recycling of the uranium and the plutonium of GEN IV MOX fuels. However, it does not fix the sensitive issue of the long-term management of the high active nuclear waste (HAW). Indeed, only the recovery and the transmutation of the minor actinides can reduce this burden down to a few hundreds of years. In this context, and in the continuity of the FP7 EURATOM SACSESS project, GENIORS focuses on the reprocessing of MOX fuel containing minor actinides, taking into account safety issues under normal and mal-operation. By implementing a three-step approach (reinforcement of the scientific knowledge $=>$ process development and testing $=>$ system studies, safety and integration), GENIORS will provide more science-based strategies for nuclear fuel management in the EU.
\end{abstract}

\section{Introduction}

The civilian use of the nuclear energy is more and more discussed in terms of global and long-term environmental impact. Whereas different studies based on life cycle assessment demonstrate the low environmental impact of the nuclear electricity, ensuring its viability [1], its social acceptance remains weak if we want to consider it as fully sustainable. This social acceptance is mainly related to the long-term management of the nuclear waste, and in particular of the high active waste (HAW) [2].

In most of the countries having deployed the nuclear energy, the spent nuclear fuel coming out of the reactor after four/five years are directly stored and considered as the ultimate waste under dry or wet conditions. So far, their very long-term disposal is not fully assessed, and it will take more than 200,000 years before their relative radiotoxicity drop down to the one the natural uranium (Fig. 1, orange curve).

In some countries, like France, a mono recycling of the spent fuel is implemented, by recovering the uranium and the plutonium from the spent fuel, manufacturing uranium oxide fuel (UOX) with the re-enriched reprocessed uranium and mixed oxide fuel (MOX) with the

\footnotetext{
* e-mail: stephane.bourg@cea.fr
}

plutonium mixed with depleted uranium from the stockpile. This reprocessing allows the saving of about $20 \%$ of uranium from the mine but also reduces the time to have a relative toxicity of the remaining ultimate waste that are conditioned under a glass form below the one of the natural uranium after 15,000 years. It also reduces the total volume of the HAW by a factor of 3.5 and the footprint of the deep geological repository by a factor of about 4 thanks to the reduced heat load of the waste allowing a higher density packing.

However, such a timeframe is still difficult to understand and apprehend for the public. Indeed, think about what our world was 15,000 years ago (Fig. 1, green curve).

To address this issue and bring back the timeframe of the nuclear waste in the human history perception, one option has been being developed for about 30 years: the partitioning and transmutation strategy ( $\mathrm{P} \& \mathrm{~T})$. It consists in recovering not only the uranium and the plutonium from the spent fuel but also the minor actinides (neptunium, americium, curium) that drive then the long-term radiotoxicity of the waste. The partitioning is the chemical process step allowing the recovery the minor actinides from the spent fuel dissolution liquor, and the transmutation is the physical process step transforming these minor actinides into short life radionuclides in fast reactors or dedicated systems (ADS). With such an approach, the relative radiotoxicity would drop below the one of the natural uranium after only 300 years (Fig. 1, blue curve). 
In fast reactors, the minor actinides would be either mixed together with the uranium and plutonium fuel (MOX, metallic, carbide or nitride fuel) (homogeneous recycling) or managed specifically in blanket fuel surrounding the $\mathrm{U} / \mathrm{Pu}$ fuel (heterogeneous recycling). In ADS, the transmutation would be operated in dedicated targets (heterogeneous recycling) (Fig. 2).

For more than 25 years, the international nuclear chemistry community has been developing different options to allow this transmutation, and particularly in Europe, under the lead of the French atomic energy and alternative energies commission (CEA). The first European project was implemented under the third framework program and is still continuing. After a wide phase of screening both in terms of general concepts and chemical systems, a few promising reference options have been selected and are now further developed. The work is now focusing on gaining a better understanding of the chemical systems under normal and mal-operation taking through a

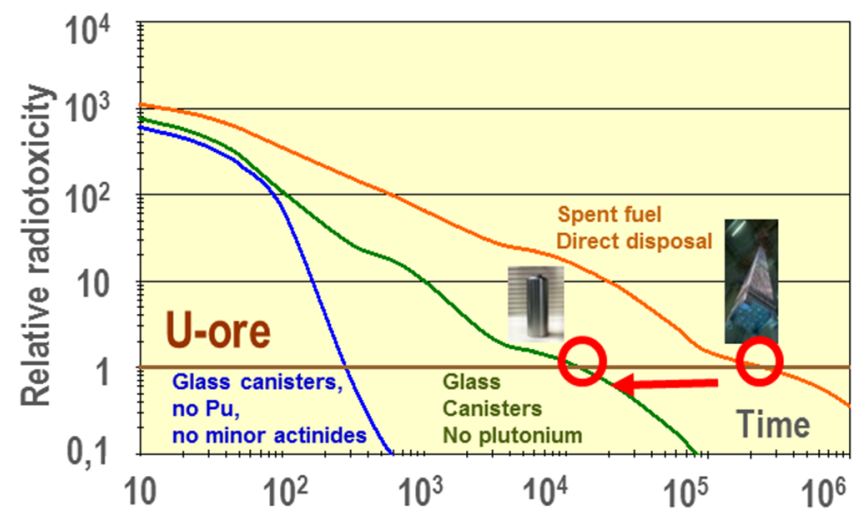

Fig. 1. Relative long-term radiotoxicity of the HAW according to their typology (credit CEA). global safety approach. Upscaling is also estimated through modelling and system studies. After a summary of the background of these studies, the work done over the last 6 years within the FP7 project SACSESS and the H2020 project GENIORS on the promising reference processes will be developed.

\section{Background}

The first European project dealing with the partitioning of the minor actinides started in 1994 (high-level liquid waste partitioning by means of completely incinerable extractants: EUR18038). Gathering CEA (France) and University of Reading (UK), it focused on the recovery of actinide cations An(III) and lanthanide cations Ln(III) from the PUREX raffinate using diamide family molecules (Fig. 3, right) and to the separation of $\mathrm{An}(\mathrm{III})$ and $\mathrm{Ln}(\mathrm{III})$ using TPTZ family molecules (2,4,6-Tris(2-pyridyl)-s-triazine) (Fig. 3, centre).

The work continued under the FP4 NEWPART part project and FP5 PARTNEW project, where a new molecule family was developed: the Bis Triazinyl Pyridine BTP replacing the TPTZ and derivatives (Fig. 3, right). The screening of new continued widely in the FP6 EUROPART project with the synthesis, characterisation and the assessment of extraction properties of more than 100 new ligands from the various families. At the end very few of them showed better properties than the previous ones, but some derivatives of the BTBPs (Bis-triazine bipyridine) (Fig. 4, left) and mainly the TODGA (Fig. 4, right),

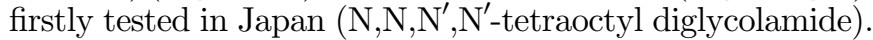

In the same timeframe, worldwide, numerous options have also been developed (SACSESS Book, http://www. sacsess.eu/Docs/SACSESS.PDF) [3]. They are summarized in Figure 5. So far, none of them have been implemented

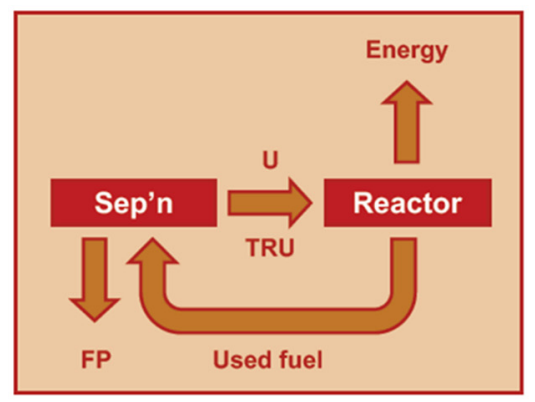

HOMOGENEOUS
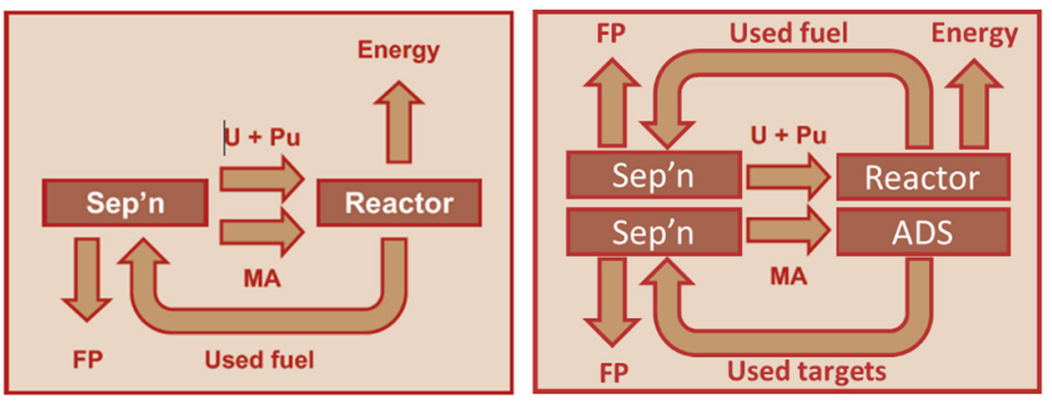

HETEROGENEOUS

Fig. 2. P\&T strategies.

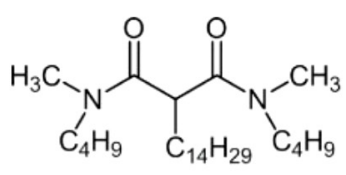<smiles>c1ccc(-c2nc(-c3ccccn3)nc(-c3ccccn3)n2)nc1</smiles><smiles>CCCc1nnc(-c2cccc(-c3nnc(CCC)c(CCC)n3)n2)nc1CCC</smiles>

Fig. 3. Diamide (DMDBTDMA), TPTZ and BTP (nPr-BTP) molecules. 


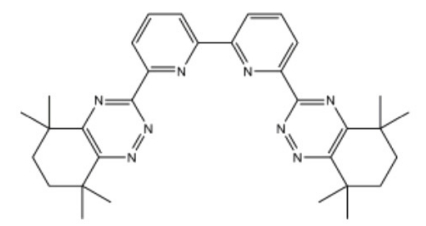

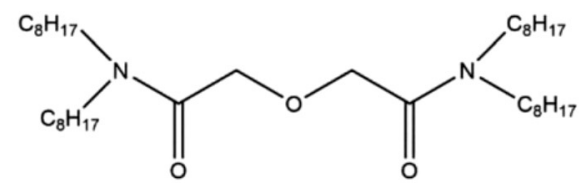

Fig. 4. CyMe4-BTBP and TODGA molecules.

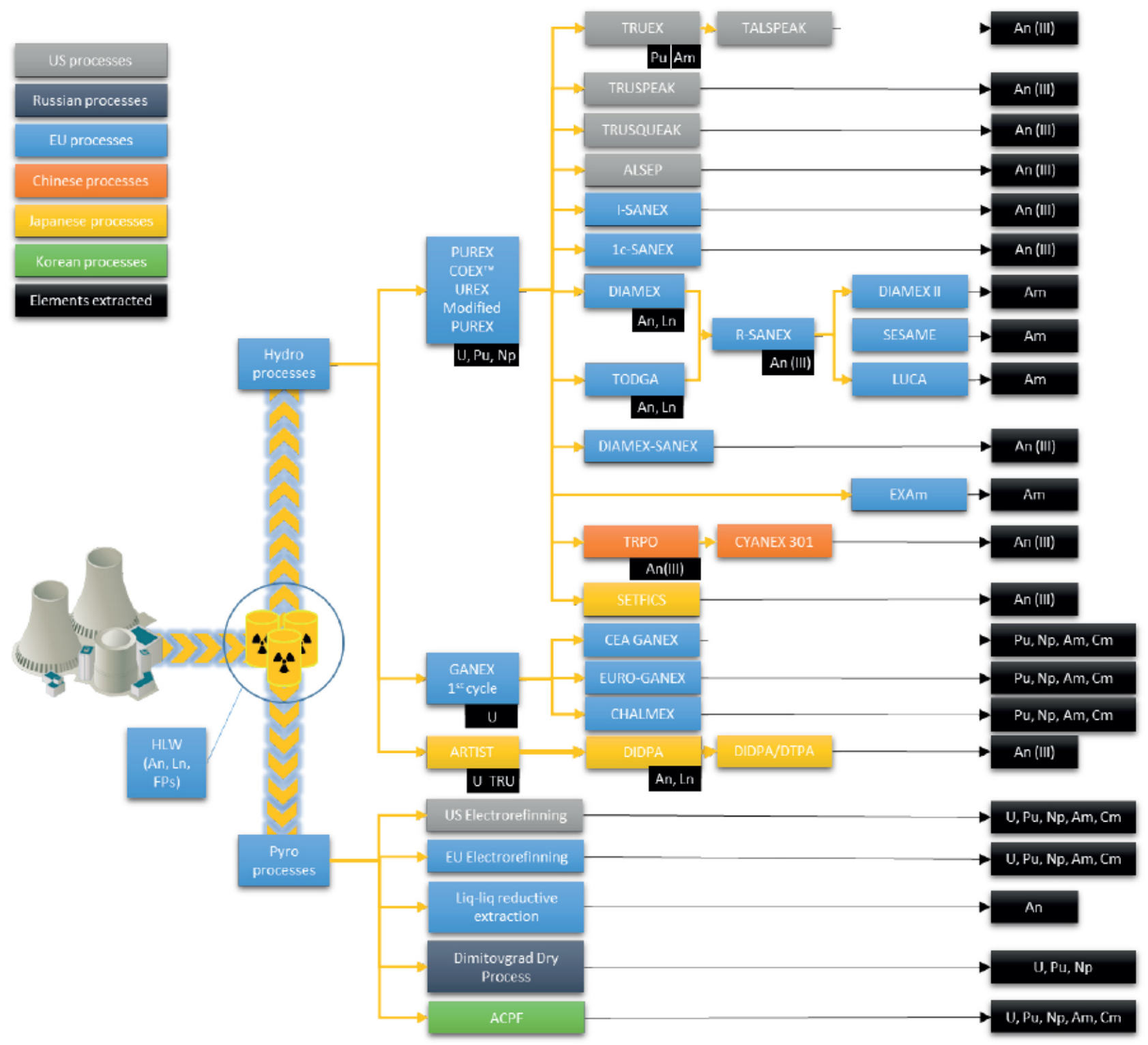

Fig. 5. Schematics of the different process options proposed worldwide the advanced reprocessing of spent nuclear fuel.

up to the industrial scale but some of them seem more promising and are still under study. Within the FP7 ACSEPT, the first schemes of the European reference processes were proposed: an innovative SANEX based on TODGA allowing the recovery of Am and Cm directly from the PUREX raffinate and the EURO-GANEX, also based on TODGA. A hot-test was performed on both flowsheet, at CEA for the i-SANEX and at ITU for the EUROGANEX.

In 2011, the Fukushima accident brought back the nuclear safety on the front scene and in this frame, the SACSESS process, follow-up of ACSEPT, designed in 2012 


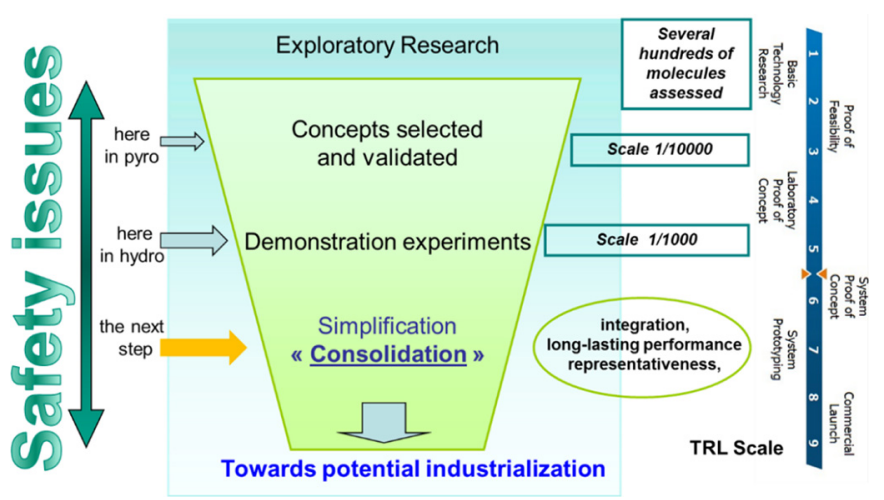

Fig. 6. The SACSESS concept.

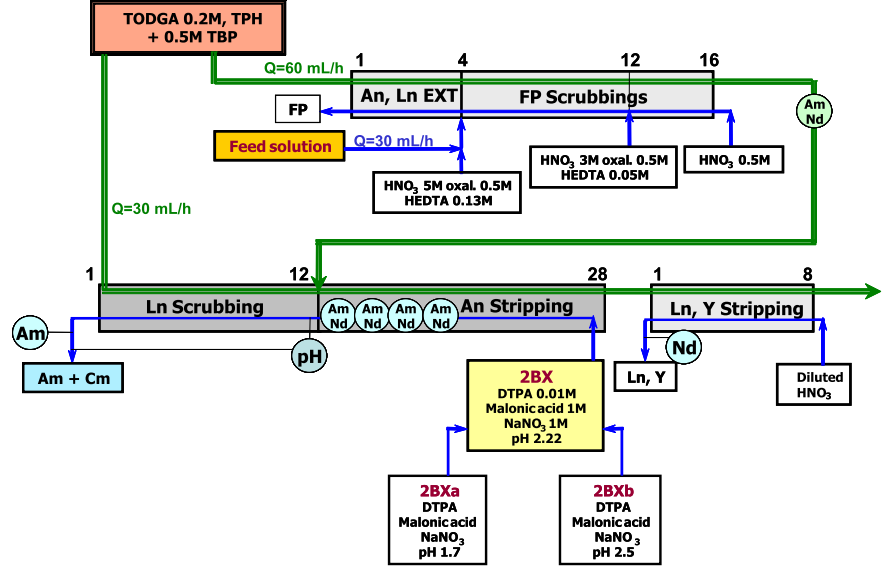

Fig. 7. The reference i-SANEX flowsheet.
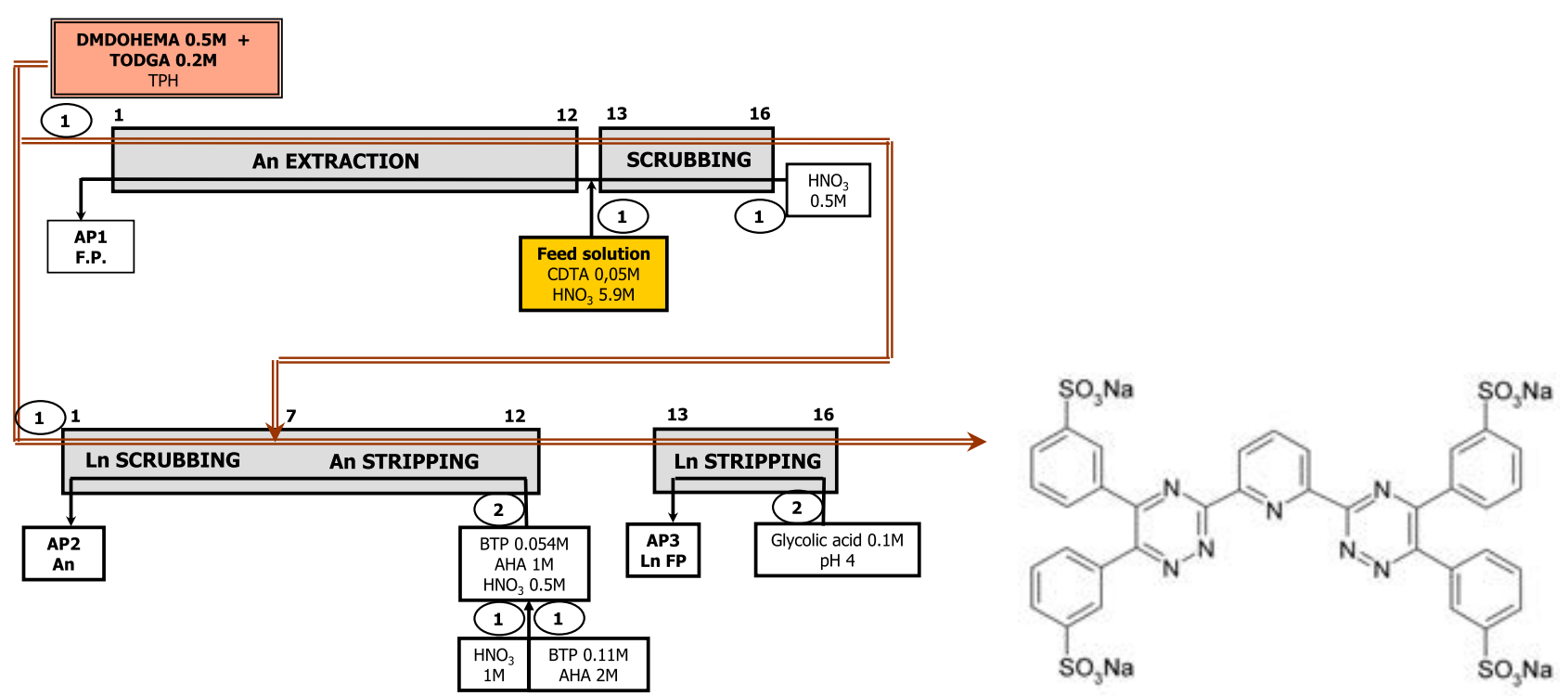

Fig. 8. The reference EURO-GANEX process.

and entered into force in March 2013 presented a very different approach than the previous project, using the safety consideration as the driver of the R\&D needs. This strategy was kept for designing the GENIORS project in 2016.

\section{SACSESS}

SACSESS started in March 2013 and ended in June 2016, with a consortium of 26 partners, a total budget of $10.5 \mathrm{M} €$ and a EU grant of $5.55 \mathrm{M} €$. The concept of SACSESS was the improvement of the reference partition processes driven by a safety approach and a technological roadmapping to identify the gap of knowledge and the $R \& D$ needs for the further developing the reference processes (Fig. 6).

\subsection{The reference processes}

The first reference process is the innovative SANEX process (i-SANEX) (Fig. 7). Based on TODGA for the An/ Ln extraction, it requires HEDTA in the feed as masking agent and DTPA and malonic acid in the stripping solution for selectively extracting the actinides.

The second reference process is the EURO-GANEX process (Fig. 8). The TODGA is also used at the extraction, together with DMDOHEMA to reduce the third phase formation risk and increase the $\mathrm{Pu}$ loading. CDTA is used as masking agent in the feed and the stripping is made thanks to an innovative molecule: the sulfonated BTP.

In addition to the i-SANEX and EURO-GANEX processes, it was decided to study also an option allowing the recovery of the americium alone from the PUREX 


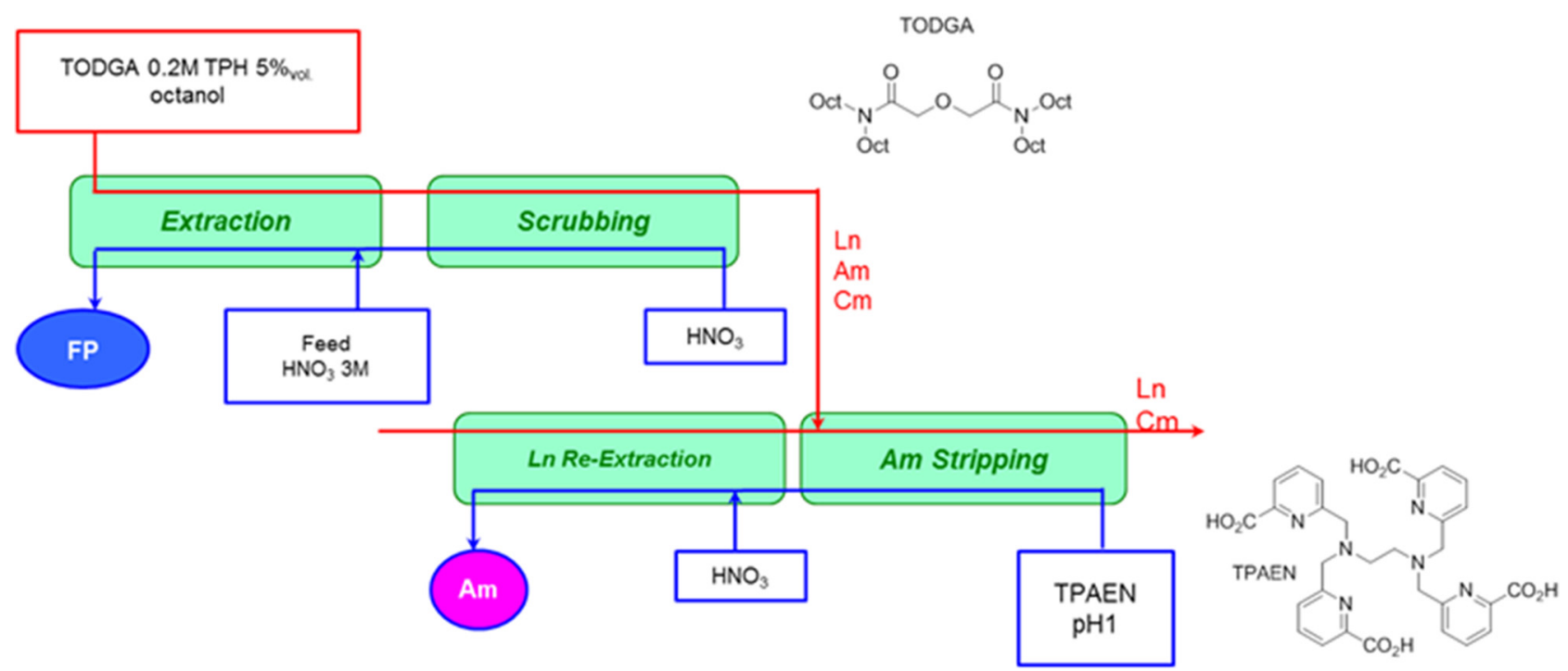

Fig. 9. The reference EURO-EXAM process.

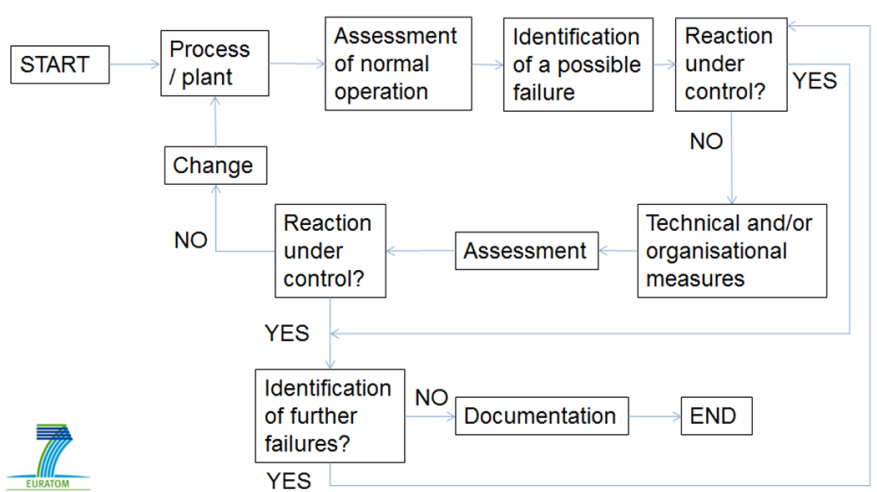

Fig. 10. The HAZOP safety methodology.

raffinate (Fig. 9). Actually, the Americium is the main contributor to the long-term radiotoxicity, once the plutonium removed, the curium is very difficult to manage once concentrated, would highly impact the design of the separation and fuel fabrication workshops, and has a halflife of 18 years allowing it to decrease during the interim repository stage of the waste management, making its impact negligible at the disposal. This process is based on an innovative molecule, the TPAEN as selective americium stripping agent whereas the extraction is very similar to the one of the i-SANEX process.

\subsection{Safety driven R\&D}

Through intereactive workhsops, the differnet process flowsheet were analysed through a safety methodology (HAZOP) (Fig. 10). This confirmed that more R\&D was needed on chemical issues:

- chemical and radiolytic stability;

- impact of degradation products / downstream effects;

- solvent clean-up.
But also, on process issues:

- loading /3rd phase formation;

- kinetics;

- losses.

In parallel, the need for more modelling at different scales, more simulation and more online analysis was pointed out.

These different topics were addressed in SACSESS, in particular the radiolytic stability issues.

The behaviour upon static gamma irradiation of TODGA, Me-TODGA, $\mathrm{CyMe}_{4}$-BTBP and $\mathrm{CyMe}_{4}{ }^{-}$ BTPhen extracting agents as well as of some diluents used to prepare organic phases was studied in detail. Also, aqueous solutions containing $\mathrm{SO}_{3}-\mathrm{Ph}-$ BTP or PyTri-diol were irradiated. The main TODGA degradation products were identified and synthesised as pure components. These products' extraction behaviour was studied to assess whether their build-up would impair the extractive properties of TODGA solvents.

Irradiation of $\mathrm{CyMe}_{4}$-BTBP and $\mathrm{CyMe}_{4}-\mathrm{BTPhen}$ diluted in 1-octanol forms a primary degradation product which was identified as an octanol adduct. This explains why $\mathrm{CyMe}_{4}$-BTBP and $\mathrm{CyMe}_{4}$-BTPhen solvents keep their extractive properties even if the $\mathrm{CyMe}_{4}-\mathrm{BTBP}$ or $\mathrm{CyMe}_{4}$-BTPhen concentration decreases upon irradiation. The compounds are not destroyed but form an adduct with similar properties.

Static irradiation of $\mathrm{SO}_{3}-\mathrm{Ph}-\mathrm{BTP}$ solutions showed the molecule to be significantly more sensitive towards radiolydic degradation than are, e.g., TODGA or $\mathrm{CyMe}_{4}-\mathrm{BTBP}$. However, a dynamic irradiation test in the irradiation loop setup at Idaho National Laboratory did not result in a deterioration of its properties.

Hydrogen generation rates (G-values) have also been determined from nitric acid and TODGA / kerosene phases 


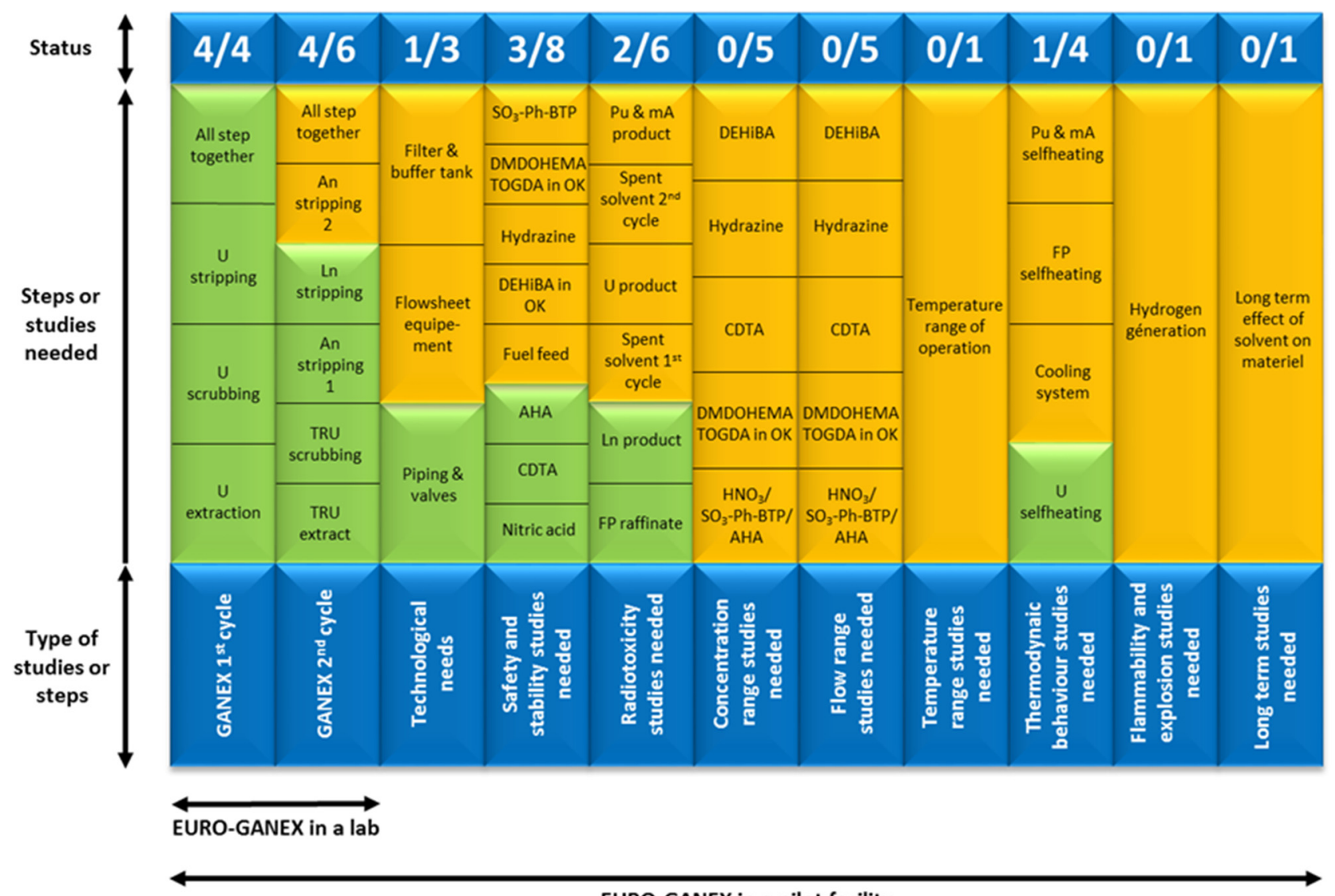

EURO-GANEX in a pilot facility

Fig. 11. Maturity level of the EURO-GANEX process.

under alpha-irradiation (from plutonium and americium ions) and compared to gamma irradiation. This is an important safety-related issue in the design of any future industrial scale process.

\subsection{Technology driven R\&D}

Studies within SACSESS have also started the key task of integrating the novel separation processes with the other parts of the overall reprocessing and recycling plant. Specifically, the effects of the aqueous phase complexing agents such as DTPA and HEDTA on the downstream product finishing process is studied. Assuming the oxalate co-precipitation process as the baseline finishing process, initial studies have considered the effects of the complexing agents on residual metal ion solubility post-oxalate precipitation. Methods of decomposing the complexants have been tested, either before oxalate precipitation or in the oxalate mother liquor before acid recycling.

A gap analysis was also conducted on the different options to identify the maturity level of the different steps (Fig. 11). The output of this work was used to design the GENIORS project.

\subsection{The EURO-EXAM process}

The lab scale data on the properties and performances of the new TPAEN led to the definition of a process flowsheet which was tested under spiked conditions at Juelich. This allowed us to highlight drawbacks that were not so impacting at the lab-scale, in particular, the quality of the TPAEN (depending on some impurities) and the very sensitive effect of the temperature which highly impact the performances. Following these tests, it has been decided to look for another chemical system.

\section{Geniors}

GENIORS started in June 2017 with 24 partners, a total budget of $7.5 \mathrm{M} €$ and an EU grant of $5 \mathrm{M} €$.

\subsection{Concept and ambition}

Based on the progress made in SACSESS, it has been decided to continue the safety and technology driven work, with an increase emphasis on the deep understanding of the mechanisms (Fig. 12). The ambition of 


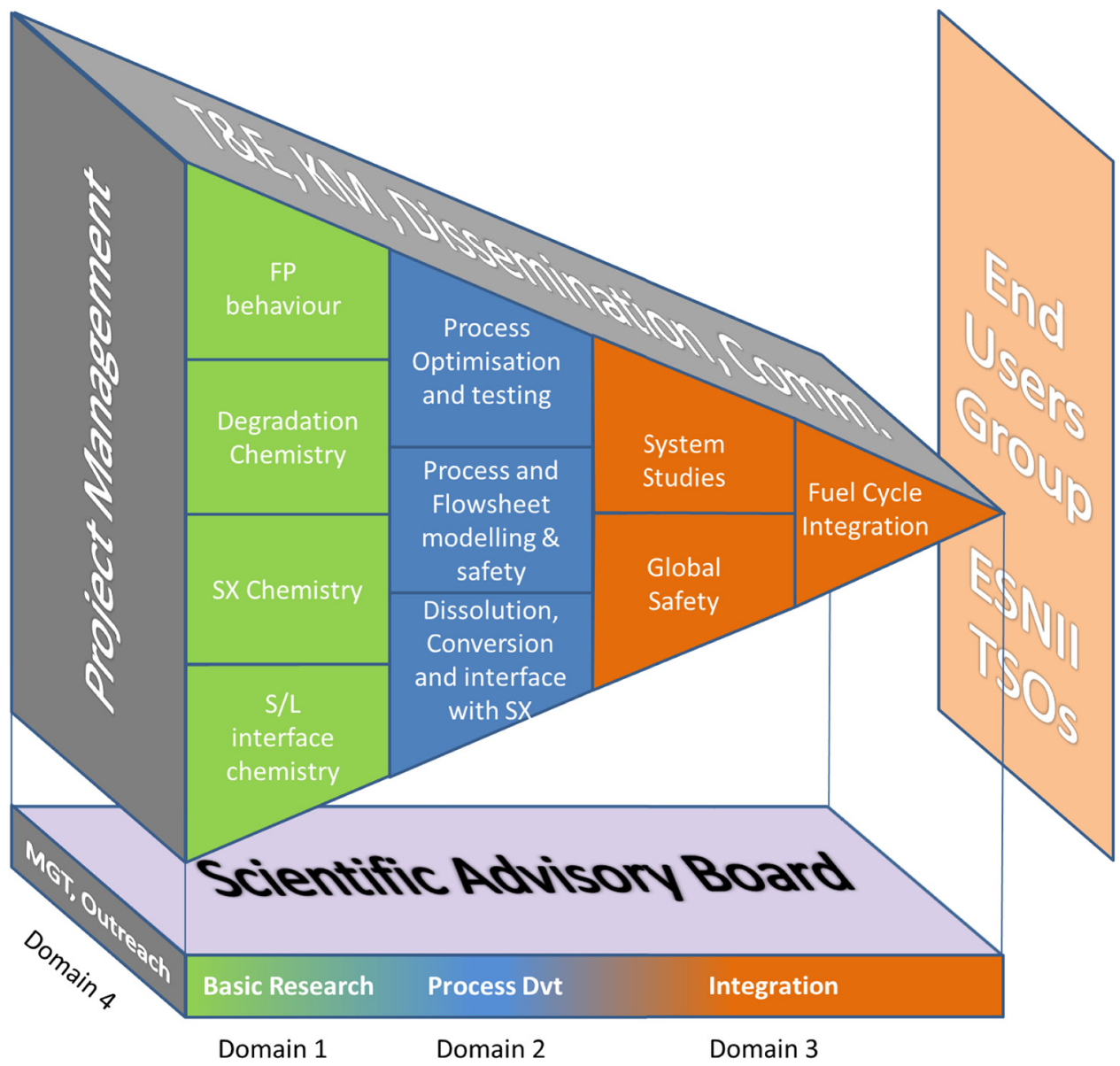

Fig. 12. Organisation of GENIORS.

GENIORS (Fig. 13) is to proceed by down-selection to keep at the end only the routes on which no weakness has been identified. In order to continue improving the reference flowsheets, four main drivers have been identified: the behaviour of problematic fission products, the radiolytic stability of the chemical systems and the impact of the degradation products including gaseous species, the process related issues (kinetics, loading, third phase) and the interface of the separation processes with the dissolution and the conversion.

\subsection{Main R\&D studies}

Following the progress and drawbacks/limitations identified in SACSESS, some key points are today under study in GENIORS.

In particular, the problem of plutonium loading and third phase formation risk in EURO-GANEX initiated an optimisation study on the TODGA. It has allowed the selection of a promising modified diglycolamide with which the use of DMDOHEMA is not needed anymore. The process is simpler. The full assessment of this new molecules is undergoing.
The interface between the separation and conversion processes highlighted that sulphur atom of the sulfonated BTP could be an issue. A new molecule (pitridiol, PTD) following the CHON principle, was selected and is under study.

Based on these new achievements, it has been decided to reconsider the i-SANEX flowsheet and simplify it but also to take benefit of this for redefining the EURO-EXAM flowsheet, without TPAEN.

An innovative back-up option is still developed: the CHALMEX process based on the use of the $\mathrm{CyMe}_{4}-$ $\mathrm{BTBP}$ in a fluorinated diluent (FS13). This process would allow a direct extraction of the TRUs from the dissolution liquor.

\subsection{System and safety studies}

The aim of this work is to propose the vision of an emerging process towards industrialisation, with a concept design of a plant and its safety review. The methodology is based on interactive brainstorming workshops, in particular combined with the training and education activities of GENIORS. The first one was organised in October 2018 in Antwerp. 


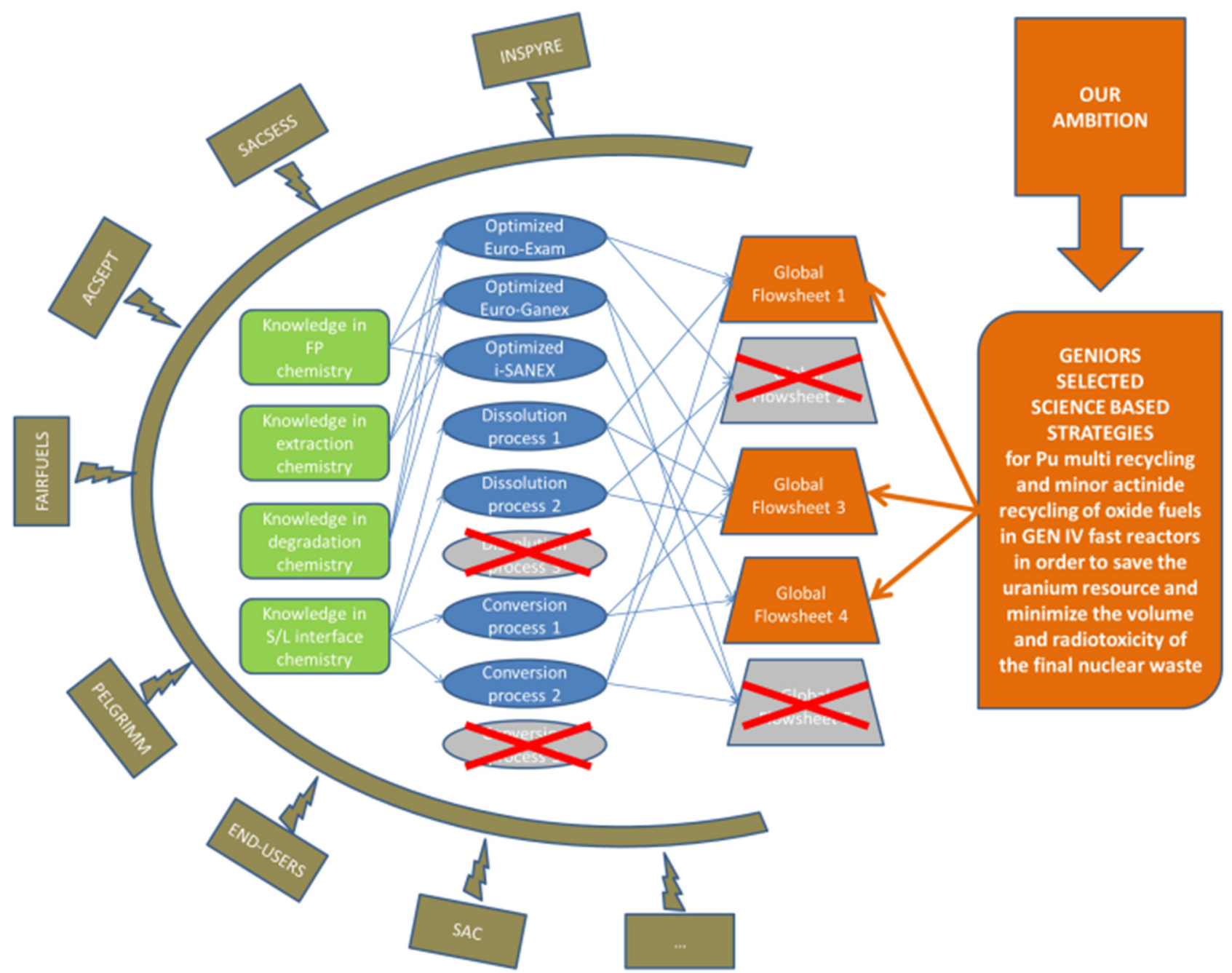

Fig. 13. The ambition of GENIORS.

\section{Conclusions}

Thanks to the European collaboration, new reference separation processes have been defined, which have excellent performances, at the level of the ones obtained at the CEA with the historic DIAMEX, SANEX, GANEX and EXAM processes. The science-based approach, driven by safety and technological considerations allows the work to be focused on the main issues. Based on this complementary information, and a better understanding of the mechanism, it will be possible to confirm the choices and reduce the number of options and keep only the most relevant, in a global vision.
Financial support for this research was provided by the European Commission via the projects GENIORS (Horizon 2020 grant agreement no. 755171) and SACSESS (FP7-Fission-2012 grant agreement no. 323282).

\section{References}

1. C. Poinssot et al., Energy 6, 199 (2014)

2. C. Poinssot et al., PiNE 92, 234 (2016)

3. P. Joly, E. Boo, SACSESS roadmap - actinide separation processes, 2015 